\title{
Consumer Adoption of Consumer-Created vs. Expert-Created Information: Moderating Role of Prior Product Attitude
}

\author{
Do-Hyung Park (D)
}

Citation: Park, D.-H. Consumer Adoption of Consumer-Created vs. Expert-Created Information: Moderating Role of Prior Product Attitude. Sustainability 2021, 13, 2024 https://doi.org/10.3390/su13042024

Academic Editor: Paweł Bryła

Received: 22 January 2021

Accepted: 9 February 2021

Published: 13 February 2021

Publisher's Note: MDPI stays neutral with regard to jurisdictional claims in published maps and institutional affiliations.

Copyright: (C) 2021 by the author. Licensee MDPI, Basel, Switzerland. This article is an open access article distributed under the terms and conditions of the Creative Commons Attribution (CC BY) license (https:// creativecommons.org/licenses/by/ $4.0 /)$.
Graduate School of Business IT, Kookmin University, Seoul 02707, Korea; dohyungpark@kookmin.ac.kr

\begin{abstract}
Today, consumer-created information such as online consumer reviews have become important and popular, playing a key role in consumer decision making. Compared with expertcreated information, each piece of information is less powerful or persuasive, but their aggregation can be more credible and acceptable. This concept is called collective intelligence knowledge. This study focuses on the persuasive effect on consumer product attitudes of consumer-created information compared to expert-created information. Using source credibility and familiarity theory, the study reveals how prior brand attitudes can play a moderating role in the persuasive effect of consumer-created information and expert-created information. Specifically, this study shows how consumer-created information is more persuasive when consumers have more favorable prior brand attitudes, while expert-created information is more persuasive when consumers have less favorable prior brand attitudes. Based on the results, this study proposes practical strategies for information structure, curation, and presentation. If a company has a good-quality brand evaluation of its products, it should increase the weight of consumer-created information such as online consumer reviews. Otherwise, the company needs to first improve brand evaluation through expert-created information such as third-parties or power-blogger reviews.
\end{abstract}

Keywords: collective intelligence; online consumer reviews; third-party reviews; source credibility; source familiarity

\section{Introduction}

Since the development of the Internet in the early 1990s, an increasing number of companies have pursued commercial activities through this "information highway". Electronic commerce, including mobile commerce, has already become a major transaction channel for daily life. By using this new information technology, electronic commerce has overcome many previous limitations (such as payments, communication, and banking); however, it maintains several online shopping limitations. Online shopping differs from traditional in-store shopping in terms of the quantity and quality of information obtained by consumers. In an online environment, consumers do not have direct contact with products and only depend on related information to purchase them. The related product information has become an important factor for influencing online consumers' attitudes and behaviors. Generally, marketers present two types of endorsements in online shopping malls for their products: (1) expert-created information such as third-party reviews or expert reviews and (2) consumer-created information such as online consumer reviews.

Expert-created information (ECI) provides independent product information (such as basic features, functions, or prices) based on lab testing or expert evaluation (examples include PC Magazine, PC World, or Car and Driver). Consumers can now easily access and compare product reviews from different sources through specialized product-review sites like consumersearch.com, which collects reviews on 170 product categories from trusted publications such as Consumer Digest and PC World. Recently, many studies have shown the important roles that expert-created information plays in consumers' purchasing decisions [1-3]. 
Consumer-created information (CCI) provides consumer-perspective product evaluation and experience [4-8]. CCI is an emerging, independent product information resource because it is likely to be more credible than seller-created information in terms of trustworthiness of the information source [9]. Also, CCI is more persuasive when greater amounts of consumer opinions are aggregated (a multiple-source effect) [5-8].

Both ECI and CCI are important information sources for consumers when they make purchase decisions, so they may have significant influential effects on online consumers' attitudes and behaviors. However, these two types of information have different information characteristics such as information concreteness, objectiveness, and user-friendliness. ECI, based on lab testing or expert evaluation, has greater expertise and professional knowledge about a product than CCI, but CCI has a higher level of perceived similarity and familiarity to consumers than ECI. Despite the differences between ECI and CCI, there remains no study that explores or compares consumer adoption of ECI and CCI.

This study focuses on the persuasive effect of ECI and CCI on consumer product attitudes. Using source credibility and familiarity theory, we suggest prior brand attitude can play a moderating role in the persuasive effect of ECI and CCI. Specifically, this study demonstrates which information (ECI vs. CCI) is more persuasive depending on prior consumer product attitudes and proposes practical information-presentation strategies based on research results.

\section{Theoretical Backgrounds and Hypotheses}

\subsection{Expert-Created Information}

ECI has grown increasingly popular in recent years. Various popular consumer magazines, including PC Magazine, PC World, Entertainment Weekly, or World Tennis, regularly publish all types of product reviews for their readers. On the other hand, the Internet has led to many third-party sources about firms' products that offer valuable information at little or no cost to consumers. Since information technologies have developed quickly and significantly reduce reviewers' information delivery cost, consumers can now easily access and compare product reviews through specialized product review sites. For example, cnet.com, zdnet.com, and caranddriver.com have grown in popularity, and a growing number of new websites are launching to offer ECI to their consumers.

The appearance and the popularity of ECI meet consumers' needs for product information because there is information asymmetry between sellers and buyers. Sellers have product information that buyers may not share (Nelson, 1974). Thus, ECI is an important information resource that reduces information asymmetry, and it is more believable and trustworthy for a consumer than information provided by sellers.

A number of studies have investigated the role of ECI. Eliashberg and Shugan [1] show that film critics influence movie box office revenue and predict the success of a movie. Reddy et al. [2] find that newspaper critics have a significant impact on the success of Broadway shows. Shaffer and Zettelmeyer [3] analyze how the provision of third-party information affects the division of profits in a multi-product distribution channel. Several studies [10-13] demonstrate how third-party reviewers design review policy to keep review information unbiased and avoid offending advertisers. These studies investigate the impact of firm advertising on third-party reviewers' policies. These studies have advanced our understanding of the effect of ECI on consumer product attitude. Kang and Park [14] showed the effects of expert reviews on product sales based on real market data.

\subsection{Consumer-Created Information}

CCI is a type of product information created by users based on personal usage experience [15-17]. It can be treated as a new element of marketing communications and functions as free "sales assistants" to help consumers identify products that satisfy their idiosyncratic usage conditions $[5,6,8,10,14-19]$. Also, CCI can be regarded as electronic word-of-mouth information because the content of this type of word-of-mouth is written digitally and shared through the Internet. 
CCI has become an important source of information to consumers, and it substitutes and complements other forms of word-of-mouth communication about the quality of various products. Many company managers believe that online comments from common consumers are significantly influential for building brand loyalty, which results in their efforts to create and manage a brand community with consumers. CCI is also considered more reliable than any other information. Since CCI is created based on the experiences of consumers' daily lives, this information can be characterized as familiar, easy to understand, and lifestyle-specific. There is additional evidence that online forums influence consumers before they make a variety of purchase decisions [18]. This study suggests that forums play an increasingly important role in public opinion formation. Online forums are, therefore, emerging as an alternative source of information to mainstream mass media, replacing our society's traditional reliance on the "wisdom of the specialist" with the "knowledge of the many" [20].

\subsection{Source Credibility of Expert-Created vs. Consumer-Created Information}

The focus of this study is to compare the differences in the influence of ECI and CCI on consumer product attitude. The literature about source credibility has advanced our understanding of the impact of ECI and CCI on consumers' attitudes and behaviors. Experimental investigations of the persuasive effect of source credibility have frequently demonstrated that highly trustworthy and expert spokespeople induce a greater positive attitude toward the position they advocate than do communicators with less credibility. Source credibility has two dimensions: expertise and trustworthiness. In a study by Dean and Biswas [21], credibility had the subdimensions of expertise (professional knowledge) and trustworthiness (unbiased communication of knowledge). Both dimensions may contribute to the persuasion effect. McGinnies and Ward [22] found that an expert who was also perceived to be trustworthy generated the most changes of opinion, but a trustworthy individual was persuasive regardless of expertise. Woodside and Davenport [23] found that an expert salesperson induced a greater number of customers to purchase a product than did a nonexpert salesperson. Finally, Ohanian [24] found that expertise (rather than trustworthiness or attractiveness) had the greatest effect on purchase intention. In addition to these two dimensions, research on communication source effects has also found that the perception that a source is similar to a receiver can also lead to an increased persuasive influence [25]. In this study, source credibility is synthesized and used in the three dimensions: expertise, trustworthiness, and similarity.

ECI and CCI are different in each of the three dimensions of expertise, trustworthiness, and similarity. First, in terms of source expertise credibility, trust in ECI depends on the recognition that experts reviewing data are qualified by either scientific training or experience evaluating such claims. Also, ECI is trusted when its view is representative of a larger group of qualified experts in the field [21]. On the other hand, CCI is a subjective review written by an anonymous person from their own perspective about the experience and evaluation they felt after using the product. Therefore, in terms of source expertise credibility, ECI's persuasive power is much stronger than that of CCI.

Second, in terms of source trustworthiness credibility, ECI has a high level of trustworthiness because it is principally published by third-party organizations whose reputation and trust are their most important value [26]. Also, CCI has a high level of trustworthiness because it is generated by independent individual consumers with no interest in sellers.

Lastly, in terms of the perceived similarity to consumers, CCI is more likely to be perceived to be similar to consumers because it is created by users with similar tastes and knowledge. On the other hand, ECI is generated by professional organizations, so it is difficult to reflect numerous consumers' experiences and voices. Consequently, CCI's perceived similarity to consumers is much higher than that of ECI. 


\subsection{The Moderating Role of Prior Product Attitude}

The higher the level of source credibility, the more persuasive the information provided by the source will be. According to cognitive response theory [27], a message recipient's initial opinion is an important determinant of the source credibility's persuasive influence. When accessing information generated from a credible source, an individual inhibits counterarguing. On the other hand, when confronted with information from less credible sources, this cognitive mechanism does not occur. Cognitive response theory predicts a highly credible communicator to have superior persuasive power. Similarly, Cook [28] suggested that individuals generate fewer counterarguments in response to a competent source than to an incompetent source. McGinnies [29] reported that a highly credible source was more persuasive than a less credible communicator when a message recipient's initial opinion toward the advocacy was very negative, but no credibility effect emerged when they held a less negative initial opinion. Dholakia and Sternthal [30] found no systematic credibility effect when an individual's prior attitude was neutral, even though a highly credible source was perceived to be more expert and trustworthy than a low credibility communicator. Dean et al. [31] reported that their highly credible source induced greater persuasion when message recipients were adamantly opposed to the communicator's position, but a less credible source was more influential when the issue was one toward which individuals were likely to have had a favorable predisposition. Similarly, Bochner and Insko [32] observed that a highly credible source was more persuasive than a moderately credible one when advocacy was highly discrepant, but the moderately credible source induced somewhat greater persuasion when the position advocated was relatively close to their initial opinion. Finally, Bock and Saine [33] found that a low credibility source was more persuasive than a highly credible source when research participants favored the advocacy.

This study attempts to consider the prior attitude toward the brand as the initial opinion that consumers have for a specific product or target. If the economic conditions allow it, consumers prefer to purchase goods from well-known brands because a brand is a well-recognized extrinsic quality cue for products [34], and a well-known brand has less purchase risk for consumers. Therefore, for the consumer who has high prior brand evaluation about a set of goods, ECI's reduction of their perceived purchase risk is not obvious. In the moment, they want to know others' opinions to confirm their own thinking, judgement, and product selection. The effect of source similarity is dominant in this low-risk condition. Therefore, the effect of CCI on a consumer's product attitude and purchase intention is more positive than ECI. In contrast, if a consumer has a low initial brand evaluation, the ECI's effect of reducing perceived purchase risk is significant for the consumer (the effect of source expertise). By contrast, consumers may not agree with CCI because CCI does not match their prior attitude. If they seek evidence to change their prior opinions, however, CCI may not be sufficient for persuasion because it may be perceived as lacking expertise. The effect of source expertise is dominant in this condition. Thus, we suggest the following hypotheses.

Hypothesis 1 (H1). When initial brand evaluation is high, consumers consider the review information created by consumers (CCI) to be more useful for purchasing decisions than the review information created by experts (ECI).

Hypothesis 2 (H2). When initial brand evaluation is high, consumers exposed to the review information created by consumers (CCI) have more favorable prior product attitudes than consumers exposed to the review information created by experts (ECI).

Hypothesis 3 (H3). When initial brand evaluation is low, consumers consider the review information created by experts (ECI) to be more useful for purchasing decisions than the review information created by consumers (CCI). 
Hypothesis 4 (H4). When initial brand evaluation is low, consumers exposed to the review information created by experts (ECI) have more favorable prior product attitudes than consumers exposed to the review information created by consumers (CCI).

\section{Research Design}

An experiment was conducted to test the hypotheses. We employed a $2 \times 2$ factorial design. The two independent variables of this experiment were information type (ECI vs. $\mathrm{CCI}$ ) and prior brand evaluation (high vs. low). First, the experiment examined whether the persuasive effect of ECI vs. CCI could be different according to information type (framing) even if the content was the same. In addition, these persuasive effects were moderated by consumers' prior brand evaluation.

Ninety-four college students voluntarily participated. Their average age was 23 years old and 72 percent were male. Random assignment to each of the cells was performed and a reward was provided to all subjects. Announcements were made during classes asking for a 20 min experiment. Subjects were randomly assigned to each of the cells in the factorial design. Most of them had purchase experience with online shopping malls and had purchased various items online. In particular, many of them had purchased electronic goods online.

The digital camera was chosen as the experiment product. There are three reasons for choosing this as the product for the experiment. First, electronic products are frequently purchased in online shopping malls. Second, consumers tend to rely on comments from previous users due to complicated manuals for electronic products. For consumers, the information obtained from sellers may not be sufficient for making a purchase decision. Third, the digital camera market is competitive and there are many products in this category. Thus, consumers need reviews to compare products and decide on the best one.

The product information pages of our selected Internet shopping mall were replicated on paper and used in the survey. These pages were similar to the product information pages of our selected popular Internet shopping mall. There was a photograph of the product, but brand names of the product were hidden to remove brand effects. The product demonstration section consisted of the product overview and its functions, which were each briefly explained. ECI and CCI were located in the following product demonstration section. To manipulate information type (ECI vs. CCI), we found real ECI from third-party organizations and magazines and revised them for the purpose of the experiment. The descriptions and recommendations from TPO about the experiment products were about its six attributes, and these were each divided by CCI, so that content was the same as ECI.

In this experiment, product attitude and perceived information quality were used as dependent variables. The measurements of product attitude refer to a respondent's overall evaluation of persons, objects, or issues. These categories were measured by seven-point numeric scales with 1 representing "extremely unlikely" and 7 representing "extremely likely". Other measurements included "favorable" vs. "unfavorable", "positively evaluative" vs. "negatively evaluative", "high quality" vs. "low quality", and "useful" vs. "useless". Finally, perceived information usefulness was defined as the degree to which information was sufficient, helpful, and confident to make a purchase decision. Questionnaire items tested this construct by asking the following: "review information is sufficient for judging product performance and quality", "the review information provides confident information about the product, so no additional information search is required", "review information is easy to compare products to other products", and "overall, review information is useful for making purchasing decisions."

Prior brand evaluation was manipulated by high and low evaluation. Low prior evaluation was manipulated as follows: "The Oregon company that manufactures and sells optical instruments such as cameras, microscopes, or telescopes. This company began in June 1926 and changed to manufacturing cameras, microscopes, telescopes, surveying instruments, glasses, and lenses for regular civil life. It had developed technology and know-how during its 85-year existence. Currently, it cannot enter into the digital camera 
field's sales order cycle and only has a $2 \%$ market share. Recently, it just manufactures its digital camera." High prior evaluation manipulated this narrative as follows: "The Oregon company that manufactures and sells optical instruments such as cameras, microscopes, telescopes, and optical instruments. This company was built in June 1926 and changed to manufacturing cameras, microscopes, telescopes, surveying instruments, glasses, and lenses for regular civil life. It manufactures trending products that are appreciated by young customers based on its technology and know-how from its 85-year existence. Currently, this company has entered into the digital camera field's third sales order cycle and has an $18 \%$ market share. Recently, it mainly manufactures its digital camera."

At the start of the experiment, the subjects were told that all the instructions were provided in the survey and that they should read the instructions carefully to complete the experiment independently. First, the subjects were manipulated to imagine different scenarios according to brand evaluation. At first, product information was provided and then either ECI or CCI was exposed. The subjects were subsequently asked to complete the same questionnaire including product attitude, perceived information usefulness, manipulation checks, and demographic information.

\section{Research Results}

\subsection{Manipulation Checks}

The subjects' responses to the four items were designed to check their perception of prior brand evaluation. An ANOVA analysis indicated the presence of a brand evaluation main effect $(\mathrm{F}(1,92)=4.740, p<0.032)$. Levene's test of homogeneity of variance for this variable yielded an insignificant result $(\mathrm{F}(1,92)=0.725, p<0.40)$, indicating that it has a homogeneous variance. Also, the normality test with the Shapiro-Wilk statistic revealed that the data has the structure of normal distribution (Shapiro-Wilk's statistic $=0.981$, $p<0.20)$. Subjects in the high-brand-evaluation condition perceived the brand to be better than subjects in the low-brand-evaluation condition (mean $=4.28$ and 3.77). This outcome offers evidence that brand evaluation was successfully manipulated.

The subjects' responses to manipulation checks relevant to information type were also examined. Five items obtained by endorsement study references were factor-analyzed. A single factor was generated with an eigenvalue of 3.55 and Cronbach's alpha of 0.85 . These were averaged for an ANOVA test. Before the ANOVA analysis, we performed both tests for homogeneity of variance and multivariate normality. Levene's test of homogeneity of variance for this variable yielded an insignificant result $(\mathrm{F}(1,92)=2.835, p<0.10)$, indicating that it has a homogeneous variance. Also, the normality test with the Shapiro-Wilk statistic revealed that the data has the structure of normal distribution (Shapiro-Wilk's statistic = $0.982, p<0.21)$. The ANOVA results demonstrated that subjects in the ECI condition had greater expertise than those in the CCI condition $(\mathrm{F}(1,92)=9.128, p<0.003$, mean $=4.4$ and 3.7). This indicates that information type was sufficiently manipulated.

\subsection{Hypotheses Testing}

Consumer product attitude, purchasing intention, and information quality were used as dependent variables. Each had a single-factor structure when factor analysis was performed. The mean and standard deviations of the dependent variables are presented in Tables 1 and 2.

To test Hypotheses 1 and 3, we needed to perform an ANOVA test for the perceived information usefulness. Since homogeneity of variance and multivariate normality had to be satisfied, two tests were conducted in advance before ANOVA analysis. Levene's test of homogeneity of variance for this variable yielded an insignificant result $(F(3,90)=1.351$, $p<0.26$ ), indicating that it has a homogeneous variance. Also, the normality test with the Shapiro-Wilk statistic revealed that the data has the structure of normal distribution (Shapiro-Wilk's statistic $=0.987, p<0.50$ ). The ANOVA test for the perceived information usefulness indicates the presence of not-significant main effects of prior brand evaluation $(\mathrm{F}(1,90)=0.065, p<0.80)$. However, the main effect of information type is not significant 
$(\mathrm{F}(1,90)=0.304, p<0.58)$. The interaction effect of prior brand evaluation and information type is significant $(\mathrm{F}(1,90)=7.749, p<0.01)$. These relationships are shown in Table 3 and Figure 1. Thus, Hypotheses 1 and 3 are both accepted.

Table 1. Descriptive statistics of dependent variable: perceived information usefulness.

\begin{tabular}{ccccc}
\hline Information Type & $\begin{array}{c}\text { Prior Brand } \\
\text { Evaluation }\end{array}$ & Mean & Std. Deviation & $\mathbf{n}$ \\
\hline $\begin{array}{c}\text { Expert-created } \\
\text { Information }\end{array}$ & Low & 4.16 & 1.032 & 24 \\
\cline { 2 - 5 } & High & 3.55 & 1.412 & 23 \\
\hline $\begin{array}{c}\text { Consumer-created } \\
\text { Information }\end{array}$ & Low & 3.63 & 1.027 & 24 \\
\cline { 2 - 5 }
\end{tabular}

Table 2. Descriptive statistics of dependent variable: product attitude.

\begin{tabular}{ccccc}
\hline Information Type & $\begin{array}{c}\text { Prior Brand } \\
\text { Evaluation }\end{array}$ & Mean & Std. Deviation & $\mathbf{n}$ \\
\hline $\begin{array}{c}\text { Expert-created } \\
\text { Information }\end{array}$ & Low & 4.55 & 1.037 & 24 \\
\cline { 2 - 5 } & High & 4.43 & 0.886 & 23 \\
\hline $\begin{array}{c}\text { Consumer-created } \\
\text { Information }\end{array}$ & Low & 3.92 & 0.776 & 24 \\
\cline { 2 - 5 }
\end{tabular}

Table 3. Descriptive statistics of dependent variable: perceived information usefulness.

\begin{tabular}{cccccc}
\hline & Type III Sum of Squares & df & $\begin{array}{c}\text { Mean } \\
\text { Square }\end{array}$ & F & Sig. \\
\hline Information Type & 0.404 & 1 & 0.404 & 0.304 & 0.583 \\
\hline $\begin{array}{c}\text { Prior Brand Evaluation } \\
\begin{array}{c}\text { Information Type } \times \\
\text { Prior Brand Evaluation }\end{array}\end{array}$ & 0.086 & 1 & 0.086 & 0.065 & 0.800 \\
\hline Error & 10.305 & 1 & 10.305 & 7.749 & 0.007 \\
\hline Total & 119.689 & 90 & 1.330 & & \\
\hline
\end{tabular}

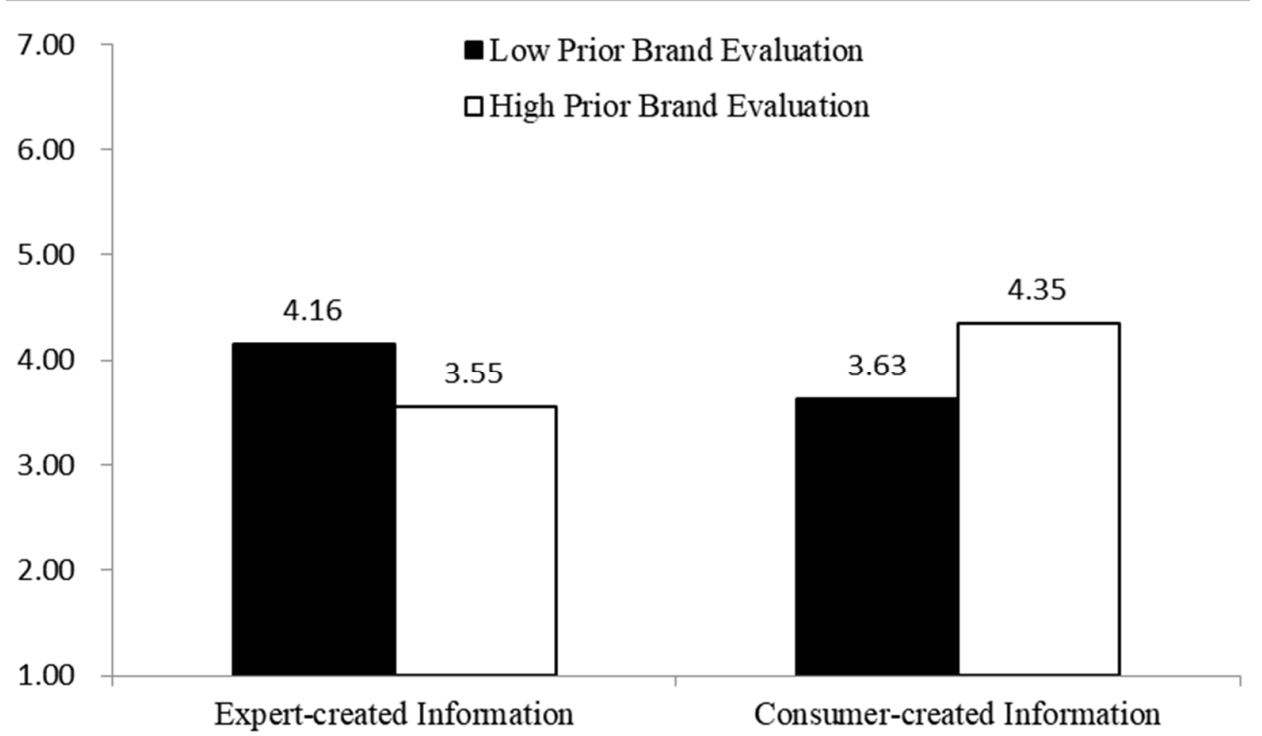

Figure 1. The result of perceived information usefulness.

To test Hypotheses 2 and 4, we needed to perform an ANOVA test for the product attitude. Since homogeneity of variance and multivariate normality had to be satisfied, two 
tests were conducted in advance before ANOVA analysis. Levene's test of homogeneity of variance for this variable yielded an insignificant result $(\mathrm{F}(3,90)=1.191, p<0.31)$, indicating that it has a homogeneous variance. Also, the normality test with the Shapiro-Wilk statistic revealed that the data has the structure of normal distribution (Shapiro-Wilk's statistic $=0.978, p<0.11$ ). The ANOVA test for the product attitude indicates the presence of significant main effects of prior brand evaluation $(\mathrm{F}(1,90)=8.106, p<0.01)$. However, the main effect of information type is not significant $(\mathrm{F}(1,90)=0.017, p<0.89)$. The interaction effect of prior brand evaluation and information type is significant $(F(1,90)=11.988$, $p<0.01$ ). These relationships are shown in Table 4 and Figure 2. Thus, Hypotheses 2 and 4 are both accepted.

Table 4. Descriptive statistics of dependent variable: product attitude.

\begin{tabular}{cccccc}
\hline & $\begin{array}{c}\text { Type III Sum of } \\
\text { Squares }\end{array}$ & df & $\begin{array}{c}\text { Mean } \\
\text { Square }\end{array}$ & F & Sig. \\
\hline Information type & 0.014 & 1 & 0.014 & 0.017 & 0.897 \\
\hline $\begin{array}{c}\text { Prior Brand } \\
\text { Evaluation }\end{array}$ & 6.921 & 1 & 6.921 & 8.106 & 0.005 \\
\hline $\begin{array}{c}\text { Information type } \\
\text { Prior Brand } \\
\text { Evaluation }\end{array}$ & 10.235 & 1 & 10.235 & 11.988 & 0.001 \\
\hline Error & 76.842 & 90 & 0.854 & & \\
\hline Total & 1997.500 & 94 & & & \\
\hline
\end{tabular}

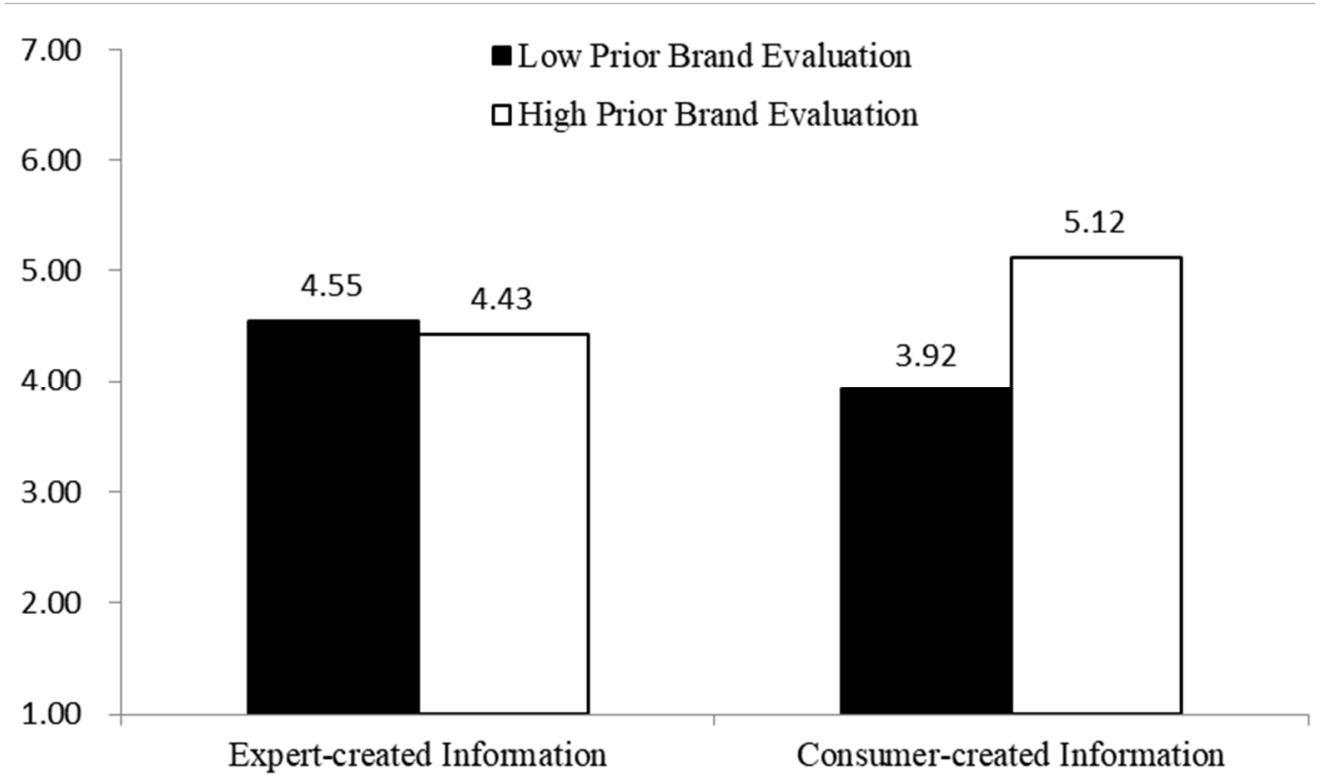

Figure 2. The result of product attitude.

In summary, all the hypotheses are accepted. Even though the same information was provided, consumers reacted differently depending on the source of the information. When their prior brand attitude is less favorable, consumers need credible sources in terms of expertise, such as ECI. Otherwise, they need familiar sources in terms of perceived similarity to consumers, such as CCI.

\subsection{Discussion}

From the viewpoint of source credibility, this study compares product review information generated by experts and product review information generated by consumers to verify which type of information is effective in a specific situation. 
As suggested by the hypotheses, the existing traditional marketing theory only sees the factors that form source credibility in two dimensions: expertise and trustworthiness $[21,22]$. In this study, the source similarity suggested in the communication effect theory is considered as another factor forming source credibility [25]. The two types of reviews provided online can have the same level of trustworthiness, if stated in a sufficiently persuasive and logical manner [22]. However, in the case of ECI, which is information generated by experts, it will be more highly recognized in terms of expertise than CCI generated by consumers [21]. However, CCI can be superior to ECI in terms of the source similarity. This is because CCI is information generated from ordinary individuals similar to consumers. Perhaps, since CCI feels more familiar, consumers are more likely to be resonated with review content. In summary, ECI has high expertise and low similarity. On the other hand, CCI is high in similarity level and low in expertise level. The fact that this study compared source credibility in terms of expertise and similarity can be a differentiated contribution from other previous studies on source credibility.

Since each review type has different advantages, the effect of each type may be different depending on the situation of the consumer. This study considers consumers' prior brand evaluations as a variable moderating these effects. When the prior brand evaluation is high, consumers are generally less risky when purchasing, whereas when it is low, consumers are riskier when making purchasing decisions. In a less risky situation, consumers need to be confident about whether this product will suit them and whether it will be usable rather than thinking about the quality or performance of the product. Therefore, through information created from information sources with higher similarity, consumers will be able to predict the usage situation more easily and project the product into their own life without difficulty. Therefore, it was verified that consumers thought CCI was more useful (Hypothesis 1), and the attitude formed through the information was higher (Hypothesis 2). On the other hand, in a riskier situation facing a brand that does not have a good attitude in advance, consumers will be motivated to reduce uncertainty about the quality or performance of the product. Therefore, it was verified that consumers perceived that ECI with expertise is more useful (Hypothesis 2), and that the consumer group who saw this information has a better product attitude (Hypothesis 4). This study has a differentiated contribution from previous studies in that it explained the conflict and internal mechanisms of expertise vs. similarity, two new perspectives of source credibility by considering the prior brand evaluation as a modulating variable.

\section{Conclusions}

In this paper, we demonstrated, depending on the value of prior brand evaluation, that source credibility has different effects on consumer product attitude. Specifically, CCI affects consumers' attitude more positively than ECI when initial brand evaluation is high. When initial brand evaluation is low, ECI affects consumers' attitude more positively than $\mathrm{CCI}$. When initial brand evaluation is high, consumer-perceived usefulness of CCI is higher than ECI. When initial brand evaluation is low, customer-perceived usefulness of ECI is higher than CCI. This occurs because ECI is not as valuable to consumers when initial brand evaluation is high, but their opinion can be supported through CCI by many other consumers. Consequently, consumers perceive CCI usefulness to be higher and to have more favorable product attitudes than ECI.

Considering there are few studies that compare ECI and CCI, this study can contribute in two ways. From a theoretical contribution perspective, this study explores the differences between ECI and CCI. Specifically, it investigated the effect of change under different initial brand evaluation levels. In a previous study [21], third-party organization endorsement affects consumers more positively than consumer endorsements. The study argued that a "third-party organization endorsement", a type of ECI, has a positive effect on changes in consumer attitudes. However, this study also argued that the effect of accurate ECI can be confirmed only when initial brand evaluation by the consumer is considered. Different than the results of a prior study [21], this study concluded that the effect of CCI and ECI can 
be reversed depending on initial brand evaluation because of the different characteristics of source credibility (expertise vs. similarity). From a practical perspective, this study's results suggest that a company's marketers could increase positive consumer attitudes when it has positive brand evaluation by accepting and referring CCI rather than ECI. When a company has less favorable brand evaluation of its products, marketers should first improve brand evaluation through ECI and subsequently increase consumer attitude through CCI.

The results of this study can be expanded with further research. Consumer side characteristics, such as motivation and knowledge, may have control-moderating effects on ECI and CCI. For example, it is necessary to consider regulatory focus and construal level, which are informational variables that consumers continuously process and are currently being studied by scholars [35-45]. Additionally, depending on product characteristics (tangible vs. intangible, actual vs. virtual), the effects of ECI and CCI can be different [40-42]. Finally, it is possible to verify whether the results of this study are viewed as real data in real situations through studies supported by larger data [46-49]. This further research will ultimately enhance our understanding of the effects of CCI and ECI.

Author Contributions: D.-H.P. designed the model, built the logic for the hypotheses, analyzed the data, and completed the insights and implementation. The author has read and agreed to the published version of the manuscript.

Funding: This work was supported by LG Yonam Foundation (of Korea). Also, this work was supported by the Ministry of Education of the Republic of Korea and the National Research Foundation of Korea (NRF-2020S1A5A2A01040055).

Institutional Review Board Statement: Ethical review and approval were waived for this study, because this study did not consider biological human experiment and patient data.

Informed Consent Statement: Informed consent was obtained from all subjects involved in the study.

Data Availability Statement: The data presented in this study are available on request from the corresponding author. The data are not publicly available due to privacy.

Acknowledgments: Do-Hyung Park thanks Yoonhee Hwang, Chaehee Park, and Chanhee Park for insightful and helpful comments.

Conflicts of Interest: The author declares no conflict of interest.

\section{References}

1. Eliashberg, J.; Shugan, S.M. Film critics: Influencers or predictors? J. Mark. 1997, 61, 68-78. [CrossRef]

2. Reddy, S.K.; Swaminathan, V.; Motley, C.M. Exploring the determinants of Broadway show success. J. Mark. Res. 1998, 35, 370-383. [CrossRef]

3. Shaffer, G.; Zettelmeyer, F. When Good News About Your Rival Is Good for You: The Effect of Third-Party Information on the Division of Channel Profits. Mark. Sci. 2002, 21, 273-293. [CrossRef]

4. Avery, C.; Resnick, P.; Zeckhauser, R. The Market for Evaluations. Am. Econ. Rev. 1999, 89, 564-584. [CrossRef]

5. Lee, J.; Park, D.-H.; Han, I. The effect of negative online consumer reviews on product attitude: An information processing view. Electron. Commer. Res. Appl. 2008, 7, 341-352. [CrossRef]

6. Lee, J.; Park, D.; Han, I. The different effects of online consumer reviews on consumers' purchase intentions depending on trust in online shopping malls. Internet Res. 2011, 21, 187-206. [CrossRef]

7. Park, D.-H.; Lee, J. eWOM overload and its effect on consumer behavioral intention depending on consumer involvement. Electron. Commer. Res. Appl. 2008, 7, 386-398. [CrossRef]

8. Park, D.-H.; Lee, J.; Han, I. The Effect of On-Line Consumer Reviews on Consumer Purchasing Intention: The Moderating Role of Involvement. Int. J. Electron. Commer. 2007, 11, 125-148. [CrossRef]

9. Wilson, E.J.; Sherrell, D.L. Source effects in communication and persuasion research: A meta-analysis of effect size. J. Acad. Mark. Sci. 1993, 21, 101-112. [CrossRef]

10. Chen, Y.; Xie, J. Third-Party Product Review and Firm Marketing Strategy. Mark. Sci. 2005, 24, 218-240. [CrossRef]

11. Park, J.; Gu, B.; Lee, H. The relationship between retailer-hosted and third-party hosted WOM sources and their influence on retailer sales. Electron. Commer. Res. Appl. 2012, 11, 253-261. [CrossRef]

12. Shugan, S.M. Marketing Perspectives on Federal Communications Commission Policies. J. Public Policy Mark. 2003, 22, 35-40. [CrossRef] 
13. Shugan, S.M. Editorial: Compartmentalized Reviews and Other Initiatives: Should Marketing Scientists Review Manuscripts in Consumer Behavior? Mark. Sci. 2003, 22, 151-160. [CrossRef]

14. Kang, T.; Park, D.-H. The Effect of Expert Reviews on Consumer Product Evaluations: A Text Mining Approach. J. Intell. Inf. Syst. 2016, 22, 63-82. [CrossRef]

15. Park, D.-H.; Park, S.-B. The multiple source effect of online consumer reviews on brand evaluations: Test of the risk diversification hypothesis. Adv. Consum. Res. 2008, 35, 744-745.

16. Park, D.-H.; Park, S.-B. The Source Diversity Effect of Online Consumer Review: Does It Help or Hurt Your Brand? Adv. Consum. Res. 2009, 36. Available online: https:/ / koasas.kaist.ac.kr/handle/10203/93857 (accessed on 12 January 2021).

17. Park, S.-B.; Park, D.-H. The Effect of Low- versus High-Variance in Product Reviews on Product Evaluation. Psychol. Mark. 2013, 30, 543-554. [CrossRef]

18. Chevalier, J.A.; Mayzlin, D. The Effect of Word of Mouth on Sales: Online Book Reviews. J. Mark. Res. 2006, 43, 345-354. [CrossRef]

19. Park, D.-H.; Kim, S. The effects of consumer knowledge on message processing of electronic word-of-mouth via online consumer reviews. Electron. Commer. Res. Appl. 2008, 7, 399-410. [CrossRef]

20. Dellarocas, C. The digitization of word of mouth: Promise and challenges of online feedback mechanisms. Manag. Sci. 2003, 49, 1407-1424. [CrossRef]

21. Dean, D.H.; Biswas, A. Third-Party Organization Endorsement of Products: An Advertising Cue Affecting Consumer Prepurchase Evaluation of Goods and Services. J. Advert. 2001, 30, 41-57. [CrossRef]

22. McGinnies, E.; Ward, C.D. Better liked than right: Trustworthiness and expertise as factors in credibility. Personal. Soc. Psychol. Bull. 1980, 6, 467-472. [CrossRef]

23. Woodside, A.G.; Davenport, J.W., Jr. The effect of salesman similarity and expertise on consumer purchasing behavior. J. Mark. Res. 1974, 11, 198-202. [CrossRef]

24. Ohanian, R. The impact of celebrity spokespersons' perceived image on consumers' intention to purchase. J. Advert. Res. 1991, 31, 46-54.

25. Price, L.L.; Feick, L.F.; Higie, R.A. Preference heterogeneity and coorientation as determinants of perceived informational influence. J. Bus. Res. 1989, 19, 227-242. [CrossRef]

26. Hertzum, M.; Andersen, H.H.; Andersen, V.; Hansen, C.B. Trust in information sources: Seeking information from people, documents, and virtual agents. Interact. Comput. 2002, 14, 575-599. [CrossRef]

27. Petty, R.E. Historical foundations of the cognitive response approach to attitudes. In Cognitive Responses in Persuasion; Richard, E., Petty, T.O., Brock, T.C., Eds.; Lawrence Erlbaum: Hillsdale, NJ, USA, 2014; pp. 5-29.

28. Cook, T.D. Competence, counterarguing, and attitude change. J. Pers. 1969, 37, 342-358. [CrossRef]

29. McGinnies, E. Initial attitude, source credibility, and involvement as factors in persuasion. J. Exp. Soc. Psychol. 1973, 9, $285-296$. [CrossRef]

30. Dholakia, R.R.; Sternthal, B. Highly Credible Sources: Persuasive Facilitators or Persuasive Liabilities? J. Consum. Res. 1977, 3, 223-232. [CrossRef]

31. Dean, R.B.; Austin, J.A.; Watts, W.A. Forewarning effects in persuasion: Field and classroom experiments. J. Pers. Soc. Psychol. 1971, 18, 210-221. [CrossRef]

32. Bochner, S.; Insko, C.A. Communicator discrepancy, source credibility, and opinion change. J. Pers. Soc. Psychol. 1966, 4, 614-621. [CrossRef]

33. Bock, D.G.; Saine, T.J. The impact of source credibility, attitude valence, and task sensitization on trait errors in speech evaluation. Speech Monogr. 1975, 42, 229-236. [CrossRef]

34. Aaker, D.A. Measuring Brand Equity across Products and Markets. Calif. Manag. Rev. 1996, 38, 102-120. [CrossRef]

35. Kim, K.-W.; Park, D.-H. Individual thinking style leads its emotional perception: Development of web-style design evaluation model and recommendation algorithm depending on consumer regulatory focus. J. Intell. Inf. Syst. 2018, 24, 171-196.

36. Park, D.-H.; Chung, J. The Effect of Consumers' Should-expectation and Will-expectation on Consumer Satisfaction: Focusing on Regulatory Focus. J. Korea Acad. Coop. Soc. 2015, 16, 8462-8471. [CrossRef]

37. Park, Y.; Park, D.-H. S/W developer's IT project participation: Focusing on the moderating role of regulatory focus on the effect of technology recency on participation intention. Knowl. Manag. Res. 2017, 18, 45-63.

38. Seo, B.-G.; Park, D.-H. Motivation of Emoticon Usage in Online Messenger Service: Focusing on Regulatory Focus. Knowl. Manag. Res. 2020, 21, 101-118.

39. Park, D.-H. Virtuality as a psychological distance: The strategy for advertisement message appeal depending on virtuality. J. Inf. Technol. Appl. Manag. 2017, 24,39-54.

40. Park, D.-H. Park Virtuality Changes Consumer Preference: The Effect of Transaction Virtuality as Psychological Distance on Consumer Purchase Behavior. Sustainability 2019, 11, 6618. [CrossRef]

41. Park, D.-H. Virtuality as a psychological distance and temporal distance: Focusing on the effect of product information type on product attitude. Knowl. Manag. Res. 2017, 18, 163-178.

42. Seo, B.-G.; Park, D.-H. The Effective Type of Information Categorization in Online Curation Service Depending on Psychological Ownership. Sustainability 2020, 12, 3321. [CrossRef] 
43. Seo, B.-G.; Park, D.-H. Did You Invest Less Than Me? The Effect of Other's Share of Investment on Psychological Ownership of Crowdfunding Projects. Sustainability 2020, 12, 2025. [CrossRef]

44. Seo, B.-G.; Park, D.-H. The effect of message framing depending on psychological ownership: Focusing on information security behavior in online service. Knowl. Manag. Res. 2018, 19, 1-18.

45. Seo, B.-G.; Park, D.-H. The effect of message framing on security behavior in online services: Focusing on the shift of time orientation via psychological ownership. Comput. Hum. Behav. 2019, 93, 357-369. [CrossRef]

46. Bae, S.D.; Park, D.-H. The Effect of Mobile Advertising Platform through Big Data Analytics: Focusing on Advertising, and Media Characteristics. J. Intell. Inf. Syst. 2018, 24, 37-57.

47. Lee, J.; Park, D.-H. Development of Customer Sentiment Pattern Map for Webtoon Content Recommendation. J. Intell. Inf. Syst. 2019, 25, 67-88.

48. Yoo, I.-J.; Park, D.-H. Derivation of Digital Music's Ranking Change through Time Series Clustering. J. Intell. Inf. Syst. 2020, 26, 171-191.

49. Yoo, I.-J.; Seo, B.-G.; Park, D.-H. Smart store in Smart City: The development of smart trade area analysis system based on consumer sentiments. J. Intell. Inf. Syst. 2018, 24, 25-52. 